\title{
Synthesis of Fructooligosaccharides by IsIA4, a truncated inulosucrase from Leuconostoc citreum
}

\author{
Arlen Peña-Cardeña, María Elena Rodríguez-Alegría, Clarita Olvera and Agustín López Munguía*
}

\begin{abstract}
Background: IsIA4 is a truncated single domain protein derived from the inulosucrase IsIA, which is a multidomain fructosyltransferase produced by Leuconostoc citreum. IIIA4 can synthesize high molecular weight inulin from sucrose, with a residual sucrose hydrolytic activity. IsIA4 has been reported to retain the product specificity of the multidomain enzyme.

Results: Screening experiments to evaluate the influence of the reactions conditions, especially the sucrose and enzyme concentrations, on IsIA4 product specificity revealed that high sucrose concentrations shifted the specificity of the reaction towards fructooligosaccharides (FOS) synthesis, which almost eliminated inulin synthesis and led to a considerable reduction in sucrose hydrolysis. Reactions with low IsIA4 activity and a high sucrose activity allowed for high levels of FOS synthesis, where $70 \%$ sucrose was used for transfer reactions, with $65 \%$ corresponding to transfructosylation for the synthesis of FOS.

Conclusions: Domain truncation together with the selection of the appropriate reaction conditions resulted in the synthesis of various FOS, which were produced as the main transferase products of inulosucrase (IsIA4). These results therefore demonstrate that bacterial fructosyltransferase could be used for the synthesis of inulin-type FOS.
\end{abstract}

Keywords: Fructosyltransferase, Fructooligosaccharides, Inulin, Inulosucrase, Leuconostoc citreum

\section{Background}

Fructooligosaccharides ( $\beta 2-1$, FOS) with a degree of polymerization (DP) in the range of $2-10$, are one of the most important sources of carbon and energy for the beneficial microbiota (probiotics) that exist in the intestinal lumen of humans [1]. FOS are generally consumed directly as part of a healthy diet, including fruit and vegetables. FOS can also be consumed indirectly through functional foods, which can be enriched with FOS obtained by the hydrolysis of chicory inulin or produced industrially through enzymatic processes with commercial fructosyltransferases (FTFs) from fungal species like Aspergillus [2]. In the latter case, fungal enzymes are the preferred choice of enzyme because of their high specificity towards low molecular weight inulins, low hydrolytic activity and high stability $[3,4]$. In contrast, bacterial inulosucrases can be used to synthesize high molecular weight inulin with low specificity towards FOS production

\footnotetext{
*Correspondence: agustin@ibt.unam.mx
Departamento de Ingeniería Celular y Biocatálisis, Instituto de Biotecnología,
Universidad Nacional Autónoma de México, Cuernavaca, Morelos C.P. 62210,

* Correspondence: agustin@ibt.unam.mx
Departamento de Ingeniería Celular y Biocatálisis, Instituto de Biotecnología,
Universidad Nacional Autónoma de México, Cuernavaca, Morelos C.P. 62210,

* Correspondence: agustin@ibt.unam.mx
Departamento de Ingeniería Celular y Biocatálisis, Instituto de Biotecnología,
Universidad Nacional Autónoma de México, Cuernavaca, Morelos C.P. 62210, México
}

[5-7]. FTFs (EC 2.4.1.-) are enzymes that catalyze the transfer of the fructosyl moiety of sucrose to different acceptors, resulting in the synthesis of fructans with different molecular weights depending on the specificity of the enzyme. The fructosyl unit can also be transferred to water, resulting in the hydrolysis of sucrose. According to the classification system for carbohydrate-active enzymes, bacterial FTFs belong to family 68 of the glycoside hydrolases (GH68). Most FTFs are 45 to $64 \mathrm{kDa}$ in length and consist of a single catalytic domain with a five-bladed $\beta$-propeller fold that encloses a funnel-like central cavity where the conserved catalytic residues are located. FTFs can be classified as inulosucrases (EC 2.4.1.9), which synthesize $\beta 2-1$ linked fructans (inulin), or levansucrases (EC 2.4.1.10), which produce fructans with $\beta 2-6$ linkages (levan) [8].

We previously reported the isolation of inulosucrase from Leuconostoc citreum CW28. This particular enzyme was designated IslA and was found to synthesize highmolecular-weight inulin. IslA is a multidomain enzyme 
containing additional regions at both the amino- and carboxyl-terminals of its catalytic domain, which are similar to those found in glucosyltransferases [9]. In this context, IslA4 is a truncated form of IslA that retains only the five-bladed $\beta$-propeller catalytic domain. IslA4 is therefore similar to several other fructosyltransferases previously reported in the literature, including the levansucrases from Bacillus subtilis (SacB) and Gluconacetobacter diazotrophicus, and the InuJ inulosucrase from Lactobacillus johnsonii NCC 533. We previously studied the effects of the additional domains of IslA on its overall properties and found that IslA4 was similar to IslA, in the sense that it produced mainly high molecular weight inulin. However, IslA4 exhibits a much higher hydrolytic activity than IslA under the same reaction conditions [10]. Interestingly, IslA developed a high level of hydrolytic activity following the elimination of some of its additional domains, and achieved similar activity to a single domain fructosyltransferase, such as levansucrase $\mathrm{SacB}$, which can hydrolyze as much as $80 \%$ of the sucrose substrate [11]. It has been demonstrated that reaction specificity (i.e., hydrolysis or transferase) as well as product specificity (i.e., type and size of fructan or FOS) in fructosyltransferases is strongly dependent on the reaction conditions, including the substrate concentration and temperature [12,13], the form in which the enzyme is applied, such as free or immobilized [14], the presence of organic solvents or co-solvents [15], and the source of the enzyme [16].

In this study, we have evaluated the effect of the reaction conditions on the specificity of IslA4 and the truncated form of inulosucrase IslA, in an attempt to identify efficient enzymes for the synthesis of inulintype FOS.

\section{Results and discussion}

Influence of substrate and enzyme concentration on IsIA4 reaction specificity

A common characteristic of fructosyltransferases is their ability to transfer the fructosyl moieties of a substrate to an acceptor molecule (the fructan growing chain) or water, leading to the hydrolysis of the substrate. The effects of the IslaA4 and sucrose concentrations on the transfer and hydrolysis reactions of the fructosyl moiety are shown in Figure 1. As in many other FTF cases, transferase activity is favored by high substrate concentrations, because of the higher amount of sucrose molecules available with respect to water for the initial transfer of the fructosyl residue [17]. Similar behavior has also been reported for levansucrase from B. subtilis, where almost $80 \%$ of the sucrose was used for transferase reactions at sucrose concentrations greater than $1,750 \mathrm{mM}$ [18]. In contrast, SacB becomes predominantly hydrolytic in terms of its activity at low sucrose concentrations (12 mM) [19]. Furthermore, levansucrase from $G$. diazotrophicus displayed only hydrolytic activity at sucrose concentrations lower than $60 \mathrm{mM}$ [20]. An inverse reaction specificity effect was observed for the enzyme concentration of IslA4, where an increase in the enzyme concentration from 1 to $10 \mathrm{U} \mathrm{mL}^{-1}$ led to an increase in the level of hydrolytic activity, regardless of the sucrose concentration. Reactions involving a low enzyme concentration and high substrate concentration (e.g., $1 \mathrm{U} \mathrm{mL}^{-1}$ and 2,046 $\mathrm{M}$, respectively) were therefore determined to be suitable reaction conditions for high transferase efficiencies, despite the lengthy reaction times required. In contrast, a high IslA4 concentration $\left(10 \mathrm{U} \mathrm{mL}^{-1}\right)$ coupled with a low sucrose concentration (292 $\mathrm{mM}$ ) led to $90 \%$ of the sucrose being hydrolyzed.

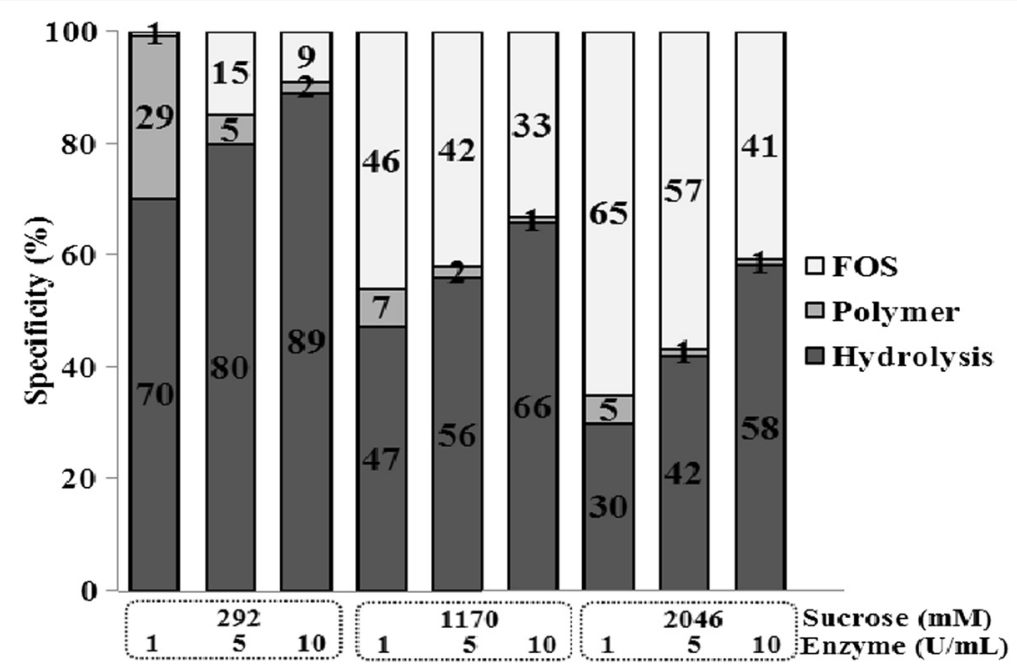

Figure 1 Transferase efficiency of IsIA4 as a function of enzyme and substrate concentration. All reactions are carried out at $30^{\circ} \mathrm{C}$ in $50 \mathrm{mM}$ phosphate ( $\mathrm{pH}$ 6.0) containing $1 \mathrm{mM} \mathrm{CaCl}_{2}$ and allowed to proceed until they reached a sucrose conversion of approximately $90 \%$. 
Similar behavior has also been reported for several other enzymes, such as $\mathrm{SacB}$ from $B$. subtilis, which transferred $78 \%$ of $1,750 \mathrm{mM}$ sucrose at low enzyme concentrations [18].

With regard to other inulosucrases, it has been reported that the transfructosylation activity of $L$. reuteri 121 increased when the substrate and enzyme concentration were increased from 200 to $1800 \mathrm{mM}$ and 40 to $130 \mathrm{U} \mathrm{mg}^{-1}$, respectively, with FOS being identified as the main transferase product together with a relatively small amount of polymeric inulin material. In contrast, the same enzyme becomes predominantly hydrolytic in its activity at concentrations lower than $200 \mathrm{mM}$ [21]. Similar results have also been reported for IslA, which became increasingly efficient in terms of ability to synthesize inulin when the initial concentration of sucrose in the reaction medium was increased [13]. Several other partially truncated forms of IslA have also exhibited similar reaction specificity behavior [10].

An extreme example of this behavior is levansucrase SacB, which shares $39 \%$ identity with inulosucrase IslA4. In this case, the enzyme concentration has a much stronger influence on the reaction specificity, with the hydrolysis of $300 \mathrm{mM}$ sucrose increasing from 67 to $98 \%$ at $35^{\circ} \mathrm{C}$ when the enzyme activity is increased from 1 to $5 \mathrm{U} \mathrm{mL}^{-1}$ [18].

\section{Product profile analysis \\ TLC analysis}

The most interesting aspect of the product specificity exhibited by IslA4 is that although IslA is responsible for the synthesis of high molecular weight inulin, the combination of a truncated domain with the appropriate reaction conditions can results in the synthesis of a wide variety of FOS as the major transferase products. This effect can be readily visualized by TLC analysis, as shown in Figure 2. In this particular case, the FOS and inulin could both be clearly seen amongst the final reaction products when the products of reactions containing $1 \mathrm{U} \mathrm{mL}^{-1}$ of enzyme activity are analyzed at three different initial sucrose concentrations. A direct comparison with standard compounds suggested that 1-kestose ( $\beta$ D-fructofuranosyl- $(2 \rightarrow 1)-\beta$-D-fructofuranosyl- $(2 \rightarrow 1)$ $\alpha$-D-glucopyranoside) would be the first acceptor product, and that this product form as a consequence of a fructosyl transfer reaction to sucrose, followed by 1 -nystose ( $\beta$-D-fructofuranosyl- $(2 \rightarrow 1)$ - $\beta$-D-fructofuranosyl- $(2 \rightarrow 1)$ $\beta$-D-fructofuranosyl- $\alpha$-D-glucopyranoside) and $f$-nystose ( $\beta$-D-fructofuranosyl- $(2 \rightarrow 1)$ - $\beta$-D-fructofuranosyl- $(2 \rightarrow 1)$ $\beta$-D-fructofuranosyl- $(2 \rightarrow 1)-\beta$-D-fructofuranosyl- $\alpha$ - Dglucopyranoside), which were only observed after an extended reaction time. However, an increase in the substrate concentration led to an increase in FOS synthesis, which was accompanied by an increase in transferase activity. Furthermore, there was a shift in the product profile with FOS with a low DP being observed at a sucrose concentration of $292 \mathrm{mM}$ (mainly 1-kestose and nystose), while FOS with a DP greater than 10 fructose units were obtained at a sucrose concentration of 2,046 mM. Inulin was formed as the major synthetic product under the standard reaction conditions (i.e., $292 \mathrm{mM}$ sucrose and

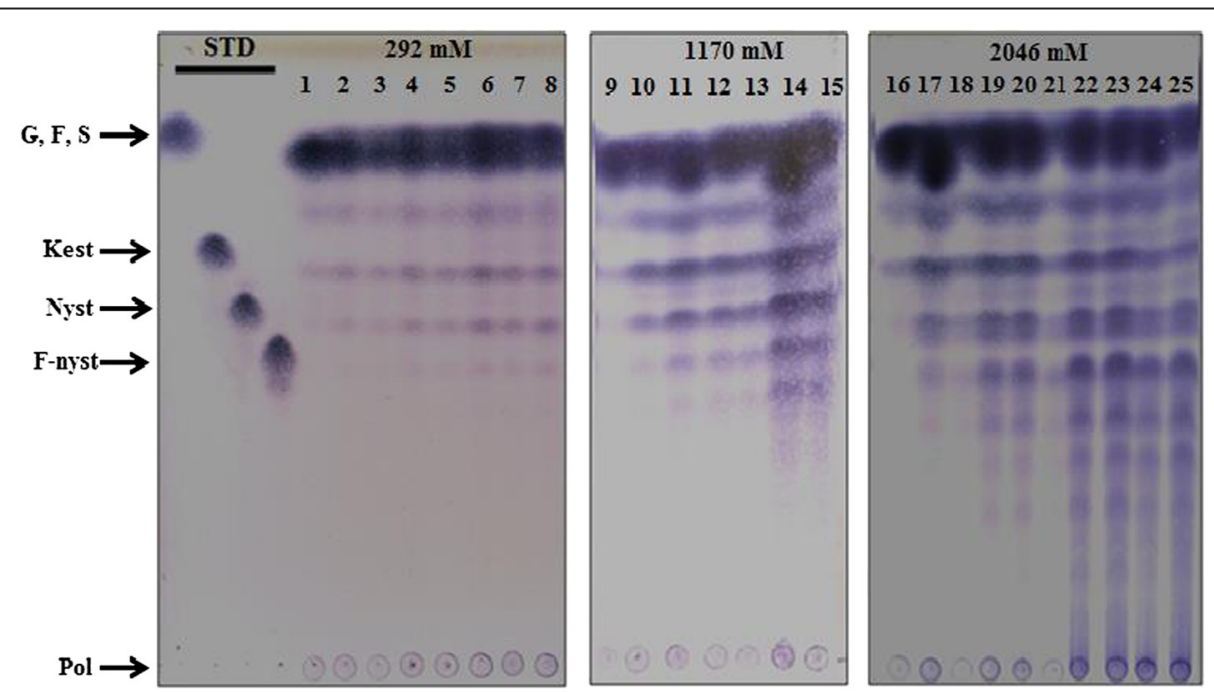

Figure 2 Influence of substrate concentration on the IsIA4 product profile, as observed by TLC. All of the reactions are carried out with $1 \mathrm{U} \mathrm{mL}$ of IsIA4 at $30^{\circ} \mathrm{C}$ in $50 \mathrm{mM}$ phosphate $\left(\mathrm{pH}\right.$ 6.0) containing $1 \mathrm{mM} \mathrm{CaCl}_{2}$, and were allowed to proceeded to a sucrose conversion of approximately $90 \%$. Samples were taken at different time points. The numbers in the figures correspond to the following reaction times: $292 \mathrm{mM}(0,2,4,6,8,10,12$ and 24 h); $1170 \mathrm{mM}(0,3,6,9,12,25$ and $34 \mathrm{~h})$; and $2046 \mathrm{mM}(0,3,6,9,12,24,27,30,34$ and 48 h). The STD lane contained the following standards: G, glucose; F, fructose; S, sucrose; Kest, 1-kestose (GF2); Nyst, 1,1-nystose (GF3); F-nyst, fructofuranosyl-nystose; and Pol, polymer. 
$1 \mathrm{U} \mathrm{mL}^{-1}$ of enzyme) using both IslA and its truncated form IslA4. Furthermore, the various FOS already described above were only observed as a small part of the product stream $[10,22]$. The reaction conditions can therefore be defined in detail to considerably reduce the inulin concentration in favor of forming FOS. In the case of L reuteri 121 inulosucrase, 1-kestose and nystose were reported to be the only products obtained from $263 \mathrm{mM}$ sucrose after $17 \mathrm{~h}$ of reaction [5]. However, an increase in the sucrose concentration to $840 \mathrm{mM}$ led to the formation of additional FOS with a DP greater than five, regardless of the inulin concentration [23]. In the same context, InuJ and InuGA, which are inulosucrases from L. johnsonii NCC 533 [6] and Lactobacillus gasseri DSM 20143 [7], respectively, can synthesize inulin together with a wide range of FOS with DP values greater than five after long reaction times in reactions containing $600 \mathrm{mM}$ of sucrose. Similar behavior has also been reported for Zymomonas mobilis levansucrase, where the product specificity shifted from levan to FOS when the sucrose concentration was increased to $800 \mathrm{mM}$ [23]. Levansucrase from Lactobacillus sanfranciscensis TMW and a truncated version of the same protein also exhibited similar behavior [24].

One important thing to consider regarding the IslA4 reaction mechanism is that the low molecular weight FOS products appear to be synthesized by a nonprocessive mechanism. In this case, all of the FOS accumulating in the solution were derived from 1-kestose, which is the first reaction product formed when sucrose is used as an acceptor (Figure 2). It has been proposed previously that subsites +2 and +3 , further away from the cleavage site $(-1$ and +1$)$, could have a low affinity for the growing FOS chains, and that these sites would then release the product once the fructosyl unit had been transferred, representing the basis of a non- processive mechanism [21]. However, this mechanism does not appear to be applicable to the case of inulin, which is most likely synthesized through a processive mechanism because inulin is only observed in the reaction medium in this case as a high molecular weight product.

\section{GPC and HPAEC-PAD analysis}

The effect of the enzyme concentration and the substrate to enzyme ratio on the molecular weight distribution of the inulin synthesized by IslA4 was analyzed by GPC, and the results are shown in Figure 3. This result clearly shows that a product with an average molecular weight of 3,000 $\mathrm{kDa}$ was obtained following $14 \mathrm{~min}$ of elution. The distribution and size of the inulin produced was therefore independent of the enzyme concentration and of lower molecular weight than inulin produced by L. reuteri 121 [5] and L. johnsonii NCC 533 [6], which reached molecular weights as high as 10,000 and $40,000 \mathrm{kDa}$, respectively. This result also revealed that high enzyme concentrations favored the hydrolysis reaction, which resulted in the synthesis of small amounts of inulin (Figure 1). This behavior can therefore be explained in terms of the interactions between the enzyme molecules or enzyme-polymer molecules rather than the availability of active sites for a given sucrose concentration.

HPAEC-PAD analysis allowed for the identification of the synthesized FOS. An HPAEC-PAD chromatogram of the products obtained at three different enzyme concentrations is shown in Figure 4. Based on the retention times of the standards, the signals obtained at $4.5,7.0,8.5,9.0$ and $11.5 \mathrm{~min}$ were attributed to 1-kestose, 6-kestose ( $\beta$-D-fructofuranosyl$(2 \rightarrow 6)-\beta$-D-fructofuranosyl-( $2 \rightarrow 6)-\alpha-D$-glucopyranoside), neokestose $(\beta$-D-Fructofuranosyl- $(1 \rightarrow 6)-\beta$-D-fructofuranosyl- $\alpha$-D-glucopyranoside), nystose and f-nystose,

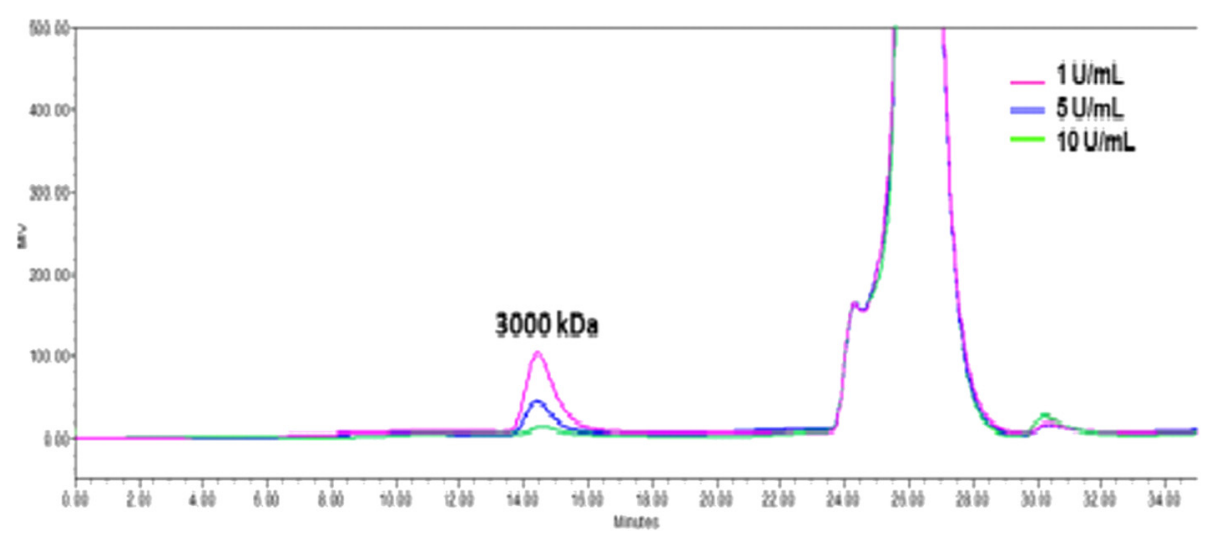

Figure 3 Influence of enzyme concentration on the molecular weight distribution of inulin synthesized by IsIA4 as observed by GPC. Reactions were carried out at three different enzyme concentrations (i.e., 1, 5 and $10 \mathrm{U} \mathrm{mL}^{-1}$ of IsIA4) with $292 \mathrm{mM}$ sucrose at $30^{\circ} \mathrm{C}$ in $50 \mathrm{mM}$ phosphate ( $\mathrm{pH}$ 6.0) containing $1 \mathrm{mM} \mathrm{CaCl} 2$, and were allowed to proceed until they reached a sucrose conversion of approximately $90 \%$. 


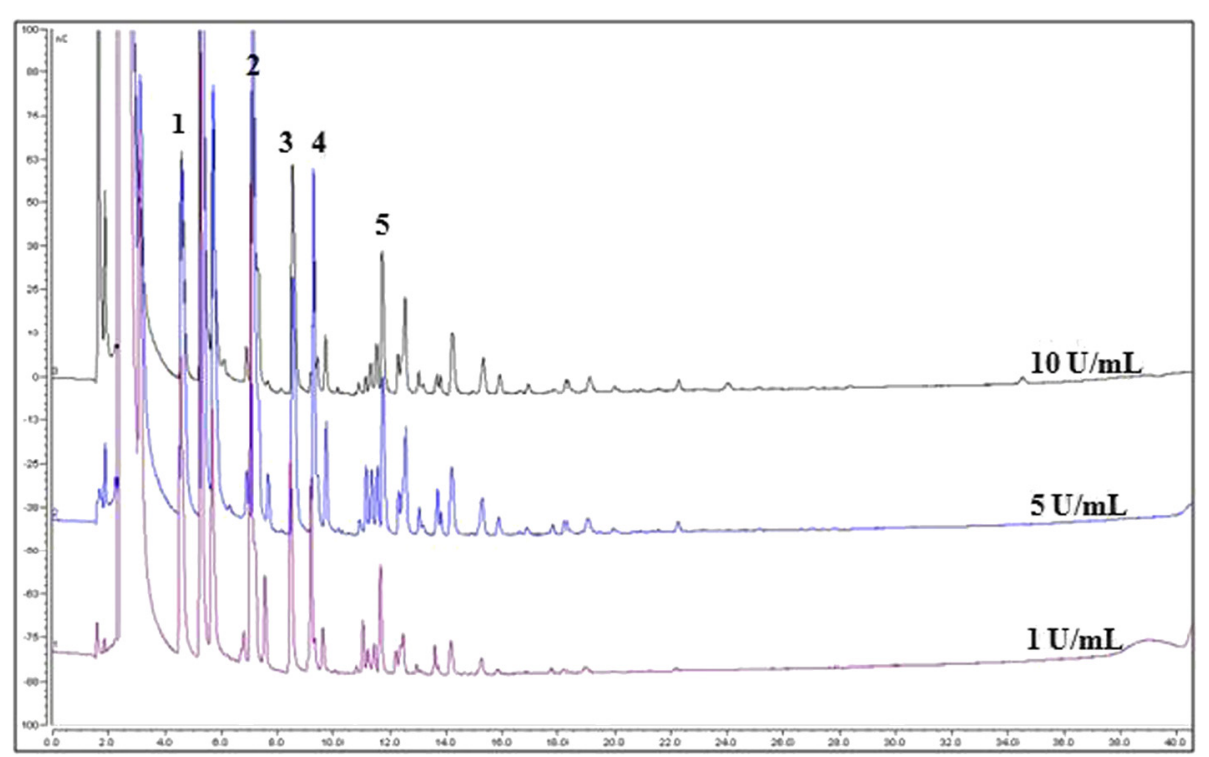

Figure 4 Influence of enzyme concentration on products synthesized by ISIA4 as observed by HPAEC-PAD analysis. Reactions were carried out at three different enzyme concentrations (i.e., 1, 5 and $10 \mathrm{U} \mathrm{mL}^{-1}$ of IsIA4) with $292 \mathrm{mM}$ of sucrose at $30^{\circ} \mathrm{C}$ in $50 \mathrm{mM}$ phosphate (pH 6.0) containing $1 \mathrm{mM} \mathrm{CaCl}_{2}$, and were allowed to proceed until they reached a sucrose conversion of approximately $90 \%$. Identified oligosaccharides: 1) 1-kestose; 2) 6-kestose; 3) neokestose; 4) nystose; and 5) f-nystose.

respectively. Although the amperometric detection intensity is not always proportional to the amount of product, the amount of synthesized FOS decreased in the current system as the molecular weight of the product increased, in a similar manner to that reported for Inu from $L$ reuteri 121 [5]. This effect can be observed quantitatively in Figure 2. Unidentified products were eluted between 1kestose and 6-kestose (products 1 and 2), and between nystose and f-nystose (products 4 and 5). Although these products have not yet been identified, the results suggest that the smallest FOS obtained after an elution time of 5 min was blastose ( $\beta$-D-fructofuranosyl- $(6 \rightarrow$ $2)-\alpha, \beta$ - $D$-glucopyranoside), which is an isomer of sucrose. Blastose could be produced by the direct transfer of fructose to glucose in C6 or by the hydrolysis of the trisaccharide neokestose (product 3), which is a transfer product resulting from the transfer of fructose to the C6-position of the glucose unit in sucrose. Interestingly, these unidentified products were also reported in inulosucrase from L. reuteri121 [5] and L. johnsonii NCC 533 [6]. However, the formation of these products does not represent a general property of inulosucrases, because these products were not observed in InuGA and InuGB from L. gasseri, where linear $\beta$ 2-1 FOS was the only FOS obtained from the direct transfer of fructose to the C1position of the fructose acceptor [7].

The highest transferase yield for the reaction was obtained at the highest sucrose concentration and the resulting FOS profile is shown in Figure 5. Once again, the reaction led to the formation of large amounts of 1-kestose, 6-kestose, neokestose, nystose and f-nystose, as well as a large amount of FOS with a DP $>5$. Despite the limitations of the separation equipment, several products were observed with retention time in excess of $20 \mathrm{~min}$. This behavior was similar to that reported for $L$. reuteri 121, which gave FOS with a higher DP than nystose when it was synthesized under high substrate concentrations [21].

\section{Quantitative analysis of the inulin and FOS synthesized by IsIA4}

The amount of fructose transferred and incorporated into inulin $\left(\mathrm{F}_{\mathrm{POL}}\right)$ was determined from a reference plot relating inulin GPC elution area to inulin concentration, which was constructed according to the procedure described above using inulin precipitated with ethanol and subsequently freeze-dried. With this methodology in hand, it was possible to demonstrate that although the inulin synthesis was independent of the substrate concentration, this factor is still an important function of enzyme concentration and activity. Overall, the level of inulin synthesis was found to be negligible at high enzyme concentrations, as shown in Table 1. These results therefore suggested that the increase in transferase activity that results from the rise in substrate concentration could be attributed to the exclusive synthesis of FOS, as already shown by TLC and HPAEC-PAD (Figures 2 and 4).

In quantitative terms, it was possible to reduce the amount of inulin from 16 to 4 or $1 \mathrm{~g} \mathrm{~L}^{-1}$ by increasing 


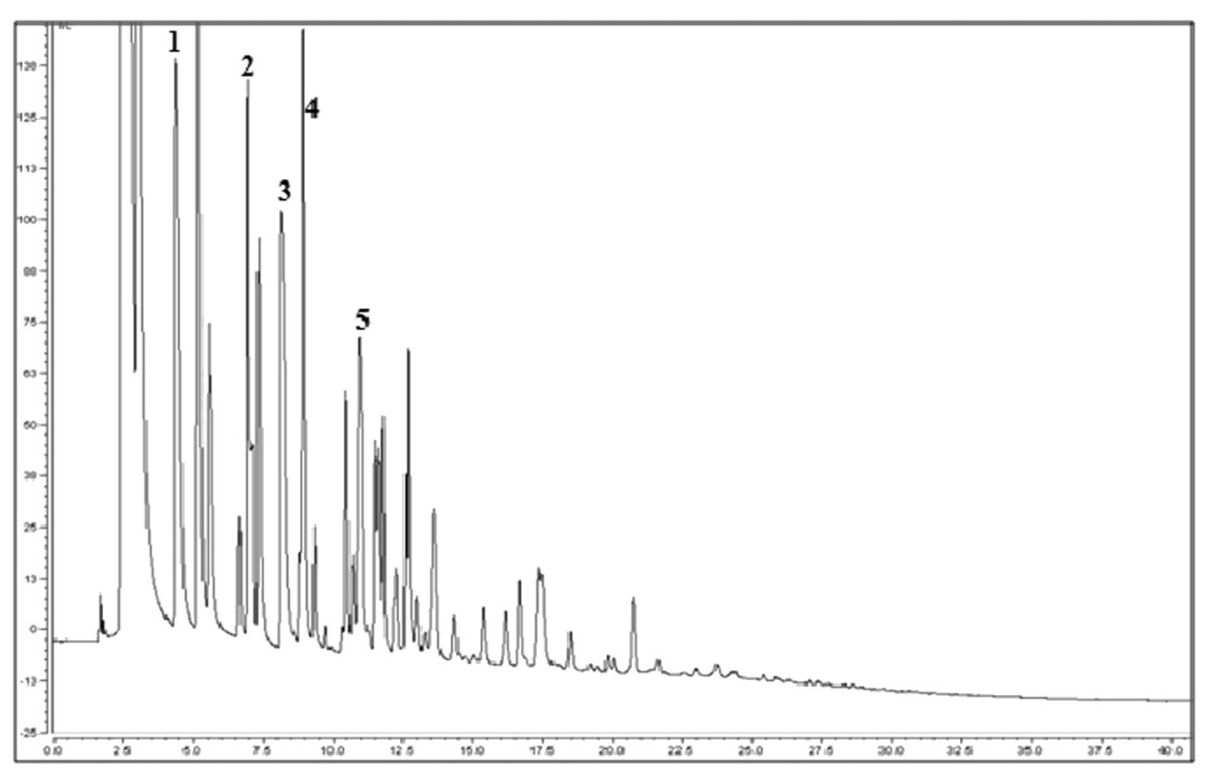

Figure 5 IsIA4 product profile under high transferase conditions as observed by HPAEC-PAD. Reactions were carried out with 2,046 mM of sucrose and $1 \mathrm{U} \mathrm{mL}^{-1}$ of IsIA4. The known oligosaccharides have been indicated as follows: 1) 1-kestose; 2) 6-kestose; 3) neokestose; 4) nystose; and 5) f-nystose.

the IslA4 concentration from 1 to 5 or $10 \mathrm{U} \mathrm{mL}^{-1}$ respectively, at any of the three sucrose concentrations studied. The highest amount of inulin produced under these reaction conditions was significantly higher than that reported for inulosucrase from L. reuteri 121, where only $0.8 \mathrm{~g} \mathrm{~L}^{-1}$ inulin was obtained from $90 \mathrm{~g} \mathrm{~L}^{-1}$ of sucrose. Although no explanation was offered for the result obtained in this particular case, the incubation times reported would only have allowed for an $18 \%$ conversion [5]. In the same context, the highest polymer yield $\left(16 \mathrm{~g} \mathrm{~L}^{-1}\right)$ obtained with IslA4 was very similar to the yield of inulin calculated for the inulosucrases InuGA

Table 1 Quantitative analysis of the products synthesized by IsIA4 under different reaction conditions used

\begin{tabular}{lllll}
\hline Sucrose (mM) & $\begin{array}{l}\text { IsIA4 } \\
\left(\mathbf{U} \mathbf{~ m L}^{-1}\right)\end{array}$ & $\begin{array}{l}\text { Sucrose } \\
\text { consumed }(\%)\end{array}$ & $F_{\mathrm{POL}}(\mathrm{mM})$ & $\mathbf{F}_{\mathrm{FOS}}(\mathbf{m M})$ \\
\hline \multirow{2}{*}{292} & 1 & $92 \pm 1.11$ & $95 \pm 4.3$ & $3 \pm 6.78$ \\
& 5 & $90 \pm 1.37$ & $18 \pm 0.4$ & $49 \pm 2.56$ \\
& 10 & $93 \pm 0.96$ & $6 \pm 0.1$ & $29 \pm 1.50$ \\
1170 & 1 & $94 \pm 0.45$ & $87 \pm 0.5$ & $584 \pm 0.12$ \\
& 5 & $93 \pm 1.59$ & $27 \pm 0.1$ & $465 \pm 0.21$ \\
& 10 & $97 \pm 1.67$ & $11 \pm 0.1$ & $407 \pm 0.10$ \\
& 1 & $87 \pm 3.40$ & $89 \pm 0.2$ & $1251 \pm 1.20$ \\
& 5 & $90 \pm 0.87$ & $23 \pm 0.2$ & $1093 \pm 0.18$ \\
& 10 & $94 \pm 2.81$ & $5 \pm 0.3$ & $808 \pm 0.05$ \\
\hline
\end{tabular}

Values shown are means \pm SD of the results from three independent experiments. and InuGB from L. gasseri, which produced 11 and $13 \mathrm{~g} \mathrm{~L}^{-1}$ of inulin, respectively, from their reactions with $205 \mathrm{~g} \mathrm{~L}^{-1}$ of sucrose [7]. In contrast, InuJ from L. johnsonii NCC 533 allowed for the synthesis of $1.5 \mathrm{~g} \mathrm{~L}^{-1}$ of inulin from $200 \mathrm{~g} \mathrm{~L}^{-1}$ of sucrose [6]. Taken together, these results suggest that IslA4 is a much more suitable enzyme for the synthesis of inulin than any of the other inulosucrases currently available, even at low substrate concentrations (292 mM), where hydrolysis is the dominant reaction pathway. However, based on the FOS concentration, $\mathrm{F}_{\mathrm{FOS}}(\mathrm{mM})$, which can be indirectly calculated according to the method described above, a low concentration of $\mathrm{F}_{\mathrm{FOS}}(\mathrm{mM})$ was obtained when the reactions were conducted at $292 \mathrm{mM}$, which was the lowest sucrose concentration evaluated (Table 1). As shown in Figure 1, these reaction conditions also induced high levels of hydrolysis, as exemplified by the reaction conducted with $10 \mathrm{U} \mathrm{mL}^{-1}$ of enzyme activity, where up to $89 \%$ of the substrate was converted to glucose and fructose. Furthermore, increasing the sucrose concentration from 1,170 to $2,046 \mathrm{mM}$ in reactions with $1 \mathrm{U} \mathrm{mL}^{-1}$ of enzyme activity, led to a two-fold increase in the amount of fructose incorporated in the FOS, despite the presence of a large amount of hydrolyzed sucrose (around $600 \mathrm{mM}$ ) in the mixture.

Figure 1 provides a detailed overview of the fate of each transferred fructose, in terms of whether it goes to water, inulin or FOS. Based on this analysis, it can be concluded that the majority of the FOS synthesis was conducted from $2046 \mathrm{mM}$ sucrose in reactions 
with $1 \mathrm{U} \mathrm{mL}^{-1}$ of enzyme, where $70 \%$ sucrose was used for transfer reactions, and $65 \%$ of this sucrose was directed towards a transfructosylation pathway for the synthesis of FOS. In contrast, the use of a low sucrose concentration $(292 \mathrm{mM})$ led not only to a decrease in the transferase reaction but also favored polymer synthesis.

\section{Conclusions}

An efficient set of reaction conditions have been established for the synthesis of FOS and/or inulin using IslA4 inulosucrase. In particular, the results of the current study have shown that the enzyme specificity can be shifted almost exclusively from the synthesis of high molecular weight inulin to the synthesis of FOS. This shift was made possible in this truncated form of the multidomain inulosucrase IslA through the careful selection of the enzyme and substrate concentration conditions. The results of the current study have also shown that the use of a high sucrose concentration in conjunction with a low IslA4 concentration results in the highly efficient synthesis of low molecular weight FOS, including 1-kestose, 6-kestose, neokestose, nystose and f-nystose.

\section{Methods}

\section{Preparation of Escherichia coli cell extracts and purification} of IsIA4

Escherichia coli BL21 cells transformed with the pET28aislA4 gene were grown in Luria-Bertani broth containing $50 \mu \mathrm{g} \mathrm{mL}{ }^{-1}$ kanamycin at $37^{\circ} \mathrm{C}$ and $120 \mathrm{rpm}$. The culture was induced with $0.2 \mathrm{mM}$ isopropyl $\beta$-D-1-thyogalactopyranoside (Gold Biotechnology, Inc., St Louis, MO USA). Once the cells reached an optical density of $0.6(600 \mathrm{~nm})$ they were incubated at $18^{\circ} \mathrm{C}$ for 6 additional hours. The cells were then harvested by centrifugation $(2,500 \times g$ for $10 \mathrm{~min}$ ) and the resulting pellet washed twice with a $50 \mathrm{mM}$ phosphate buffer (pH 6.0) containing $1 \mathrm{mM} \mathrm{CaCl}_{2}$ before being re-suspended in $5 \mathrm{~mL}$ of the same buffer containing pepstatin $\left(0.7 \mu \mathrm{g} \mathrm{mL} \mathrm{m}^{-1}\right)$ and Complete (one tablet to $50 \mathrm{~mL}$ of cell extract), which were added as protease inhibitors, and sonicated. Cell debris was removed by centrifugation $(21,130 \times g$ for $30 \mathrm{~min})$ and the supernatant containing the enzyme was recovered for further processing. The protein concentration was determined according to the Bradford method [25] using the Bio-Rad reagent, with bovine serum albumin (BSA) (albumin fraction V; Sigma Aldrich, St. Louis, MO, USA) being used as a standard. The enzyme was purified by His-tag affinity chromatography. A bed volume of $600 \mu \mathrm{L}$ of $\mathrm{Ni}$-nitroacetic acid (Ni-NTA) resin (Qiagen) was used to bind the protein from $5 \mathrm{~mL}$ of cell extract. The resin was equilibrated with $500 \mu \mathrm{L}$ of $\mathrm{pH} 7.0$ binding buffer containing $50 \mathrm{mM} \mathrm{NaH} \mathrm{PO}_{4}, 300 \mathrm{mM} \mathrm{NaCl}$ and
$10 \mathrm{mM}$ imidazole. The cell extract was diluted with an equivalent amount of the binding buffer and incubated overnight at $4^{\circ} \mathrm{C}$ under agitation with the equilibrated resin. The proteins from the extract were subsequently eluted from the resin by successive additions of buffer, with increasing amounts of imidazole (i.e., 30, 60 and $100 \mathrm{mM}$ of imidazole). Finally, the enzyme was eluted with buffer containing $250 \mathrm{mM}$ imidazole. The protein was dialyzed against $50 \mathrm{mM}$ phosphate buffer ( $\mathrm{pH}$ 6.0) containing $1 \mathrm{mM}$ $\mathrm{CaCl}_{2}$ and concentrated by ultrafiltration on an Amicon Ultra centrifugal Filter 10,000 NMWL (Merck Millipore, Billerica, MA, USA). The purity of IslA4 was verified by $10 \%$ SDS-PAGE (Figure 6); it shows an adequate level of enzyme purity.

\section{Activity assay}

In order to have a general idea of the enzyme activity, initial reaction rates were measured at $30^{\circ} \mathrm{C}$ in $50 \mathrm{mM}$ phosphate buffer ( $\mathrm{pH}$ 6.0) containing $1 \mathrm{mM}$ $\mathrm{CaCl}_{2}$ in the presence of $292 \mathrm{mM}$ sucrose. The global activity was expressed as the reducing sugars released from sucrose using the 3,5-dinitrosalicylic acid method (DNS) [26]. One global activity unit (U) was defined as the amount of enzyme required to produce $1 \mu \mathrm{mol}$ of reducing sugars per minute. The specific hydrolysis and transferase activities were

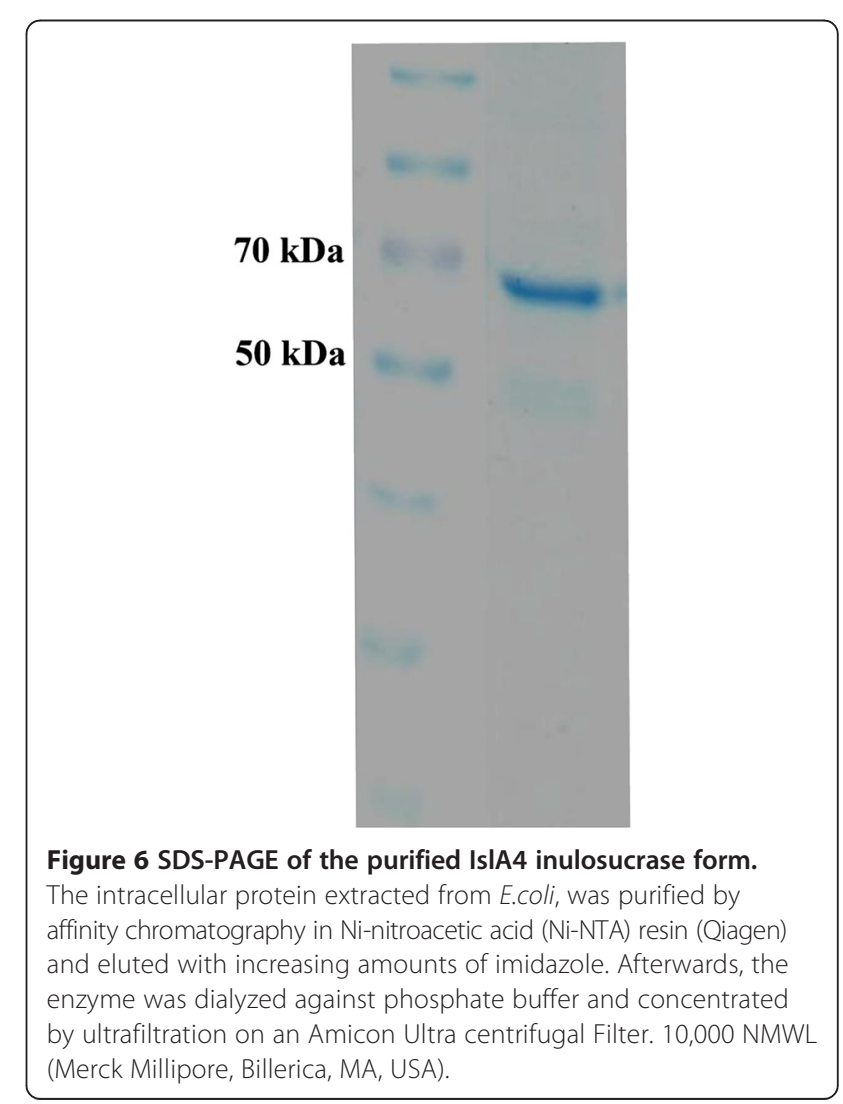


measured by HPLC based on the amounts of fructose and glucose. The HPLC method used in the current study is described below.

\section{Influence of reaction conditions on IsIA4 product and reaction specificity}

The enzymatic synthesis was carried out at $30^{\circ} \mathrm{C}$ in $50 \mathrm{mM}$ phosphate (pH 6.0) containing $1 \mathrm{mM} \mathrm{CaCl}_{2}$ at three different sucrose (292, 1,170 and 2,046 mM) and enzyme (1, 5 and $\left.10 \mathrm{U} \mathrm{mL}^{-1}\right)$ concentrations to evaluate the influence of the reaction conditions on the product and reaction specificities of IslA4. All of the reactions were allowed to proceed until they reached a sucrose conversion of approximately $90 \%$. The reaction specificity (i.e., hydrolysis to transferase ratio) was determined by measuring the amounts of glucose and fructose released during the reaction. Free glucose (Gf) was derived from hydrolyzed sucrose as well as the sucrose that was used as a fructose donor for the transferring reactions, whereas free fructose (Ff) was derived exclusively from the hydrolytic activity of the enzyme. The difference between the amounts of consumed and hydrolyzed sucrose could therefore be used to determine the amount of fructose used for transfructosylation (Ft), i.e., the transferase activity.

\section{FOS, sugars and fructan analysis}

\section{TLC analysis of the oligosaccharide profile}

The oligosaccharides produced by IslA4 were analyzed by TLC using silica gel 60 glass plates (Merck, Darmstadt, Germany). Samples were taken at different reaction times and spotted $(1 \mu \mathrm{L})$ onto a TLC plate. Fructose, glucose and sucrose (Sigma Aldrich), and 1-kestose (GF2) nystose (GF3) and fructofuranosyl-nystose (Wako Pure Chemical Industries) were used as standards. The TLC plates were ran twice using a 15:9:6 (v/v/v) mixture of ethanol, butanol and water as the mobile phase. The plates were then air-dried and sprayed with an alcoholic solution of $\alpha$-naphthol before being heated at $150^{\circ} \mathrm{C}$.

\section{Sugars analysis}

Sugars were quantified by high-pressure liquid chromatography (HPLC) using a Waters 600E system controller (Waters Corp. Milford, MA, USA) equipped with a refraction index detector (Waters 410) using a Prevail Carbohydrate ES column $(250 \times 4.6 \mathrm{~mm})$ at $30^{\circ} \mathrm{C}$. The HPLC system was eluted with a mobile phase consisting of a 75:25 (v/v) mixture of acetonitrile and water at a flow rate of $1.0 \mathrm{~mL} \mathrm{~min}^{-1}$. The molecular weight of the Inulin was determined by gel permeation chromatography (GPC) using a serial set of Ultrahydrogel (UG 500 and linear) columns at $30^{\circ} \mathrm{C}$.
The columns were eluted with a mobile phase sodium nitrate $100 \mathrm{mM}$ at a flow rate of $0.8 \mathrm{~mL} \mathrm{~min}^{-1}$. Oligosaccharides were separated and analyzed by highperformance anion exchange chromatography with pulsed amperometric detection (HPAEC-PAD, Dionex), using a CarboPac PAD-200 column $(250 \times 2 \mathrm{~mm})$. The following gradient was used: eluent $\mathrm{A}$ at $100 \%$ (0 min), 99\% (0.5 $\mathrm{min}$ ), 80\% (25 $\mathrm{min}$ ), 20\% (85 min) and 100\% (95 min). Eluent A was $150 \mathrm{mM}$ sodium hydroxide and eluent B was $150 \mathrm{mM}$ sodium hydroxide in $500 \mathrm{mM}$ sodium acetate.

\section{Quantitative analysis of the products synthesized by IsIA4}

The polymer was precipitated from the supernatant by the addition of 2 volumes of cold $96 \%$ ethanol followed by centrifugation $(2500 \times g$ at $30 \mathrm{~min})$. The material was then dissolved in MilliQ water and dialyzed against $50 \mathrm{mM}$ phosphate buffer ( $\mathrm{pH}$ 6.0) containing $1 \mathrm{mM} \mathrm{CaCl}_{2}$, and the resulting polymers were freeze-dried and occupied to produce a standard curve, which was used to calculate the amount of fructose incorporated into the polymer $\left(\mathrm{F}_{\mathrm{POL}}\right)$. For quantitative purposes, the level of fructose incorporated exclusively into FOS $\left(\mathrm{F}_{\mathrm{FOS}}\right)$ was defined as the difference between $\mathrm{Ft}$ and $\mathrm{F}_{\mathrm{POL}}$ (i.e., $\mathrm{F}_{\mathrm{FOS}}=\mathrm{Ft}-\mathrm{F}_{\mathrm{POL}}$ ). Although this method meant that the amount of fructose incorporated into FOS was calculated in an indirect manner, the results still allowed for a comparative analysis.

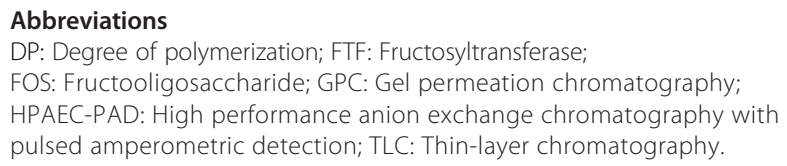

\section{Competing interests}

The authors declare that they have no competing interests.

\section{Authors' contributions}

APC: Conducted most of the experimental work as part of her MSc thesis. APC also wrote the preliminary manuscript. MERA: Provided technical support, conducted preliminary and complementary experiments, and was actively involved in general project discussions, as well as reviewing the manuscript. CO: Isolated the original enzyme and constructed the truncated versions. CO was also actively involved in general project discussions. ALM: Research director. Designed the project, conducted the research and wrote the final version of the manuscript. All authors read and approved the final manuscript.

\section{Acknowledgments}

This project was supported by PAPIIT-UNAM No. IN212311. Arlen Peña-Cardeña thanks CONACYT, México for her master scholarship (No. 254166). The authors would like to thank Fernando Gonzalez, Juan Manuel Hurtado and Roberto Rodriguez for technical support.

Received: 23 September 2014 Accepted: 23 January 2015 Published online: 07 February 2015

\section{References}

1. Biedrzycka E, Bielecka M. Prebiotic effectiveness of fructans of different degrees of polymerization. Trends Food Sci Tech. 2004;15:170-5.

2. Chi Z, Chi Z, Zhang T, Liu G, Yue L. Inulinase-expressing microorganism and applications of inulinases. Appl Microbiol Biotechnol. 2009;82:211-20.

3. Godshall MA. Future directions for the sugar industry. Int Sugar J. 2001;103:378-84. 
4. Yun JW. Fructooligosaccharides-occurrence, preparation, and application. Enzyme Microb Technol. 1996;19:107-17.

5. van Hijum SAFT, van Geel-Schutten GH, Rahaoui H, van der Maarel MJEC, Dijkuizen L. Characterization of a novel fructosyltransferase from Lactobacillus reuteri that synthesizes high-molecular-weight inulin and inulin oligosaccharides. Appl Environ Microbiol. 2002;68:4390-8.

6. Anwar MA, Kralj S, van der Maarel MJEC, Dijkhuizen L. The probiotic Lactobacillus johnsonii NCC 533 produces high-molecular-mass inulin from sucrose by using an inulosucrase enzyme. Appl Environ Microbiol. 2008;74:3426-33.

7. Anwar MA, Kralj S, Villar Piqué A, Leemhuis H, van der Maarel MJEC, Dijkhuizen L. Inulin and levan synthesis by probiotic Lactobacillus gasseri strains: characterization of three novel fructansucrase enzymes and their fructan products. Microbiology. 2010;156:1264-74.

8. van Hijum SA, Kralj S, Ozimek LK, Dijkhuizen L, van Geel-Schutten IG Structure-function relationships of glucansucrase and fructansucrase enzymes from lactic acid bacteria. Microbiol Mol Biol Rev. 2006:70:157-76.

9. Olivares-Illana V, López-Munguía A, Olvera C. Molecular characterization of inulosucrase from Leuconostoc citreum: a fructosyltransferase within glucosyltransferase. J Bacteriol. 2003;185:3606-12.

10. Del Moral S, Olvera C, Rodríguez ME, López-Munguía A. Functional role of the additional domains in inulosucrase (Is|A) from Leuconostoc citreum CW28. BCM Biochem. 2008;9:6. doi:10.1186/1471-2091-9-6.

11. Ortiz-Soto ME, Rivera M, Rudiño-Piñera E, Olvera C, López-Munguía A. Selected mutations in Bacillus subtilis levansucrase semi-conserved regions affecting its biochemical properties. Protein Eng Des Sel. 2008;21:589-95.

12. Tanaka T, Oi S, Yamamoto T. Synthesis of Levan by Levansucrase. Some factors affecting the rate of synthesis and degree of polymerization of levan. J Biochem. 1979;85:287-93.

13. Ortiz-Soto ME, Olivares-IIlana V, López-Munguía A. Biochemical properties of inulosucrase from Leuconostoc citreum CW28 used for inulin synthesis. Biocatal Biotrans. 2004;22:275-81.

14. Chambert R, Petit-Glatron MF. Immobilisation of levansucrase on calcium phosphate gel strongly increases its polymerase activity. Carbohydrate Res. 1993;244:129-36.

15. Castillo E, López-Munguía A. Synthesis of levan in water-miscible organic solvents. Biotechnol. 2004;114:209-17.

16. Falconer DJ, Rupendra M, Robyt JF. Biosynthesis of dextrans with different molecular weights by selecting the concentration of Leuconostoc mesenteroides B-512FMC dextransucrase, the sucrose concentration, and the temperature. Carbohydr Res. 2011;346:280-4.

17. Chuankhayan P, Hsieh CY, Huang YC, Hsieh YY, Guan HH, Hsieh YC, et al. Crystal structures of Aspergillus japonicus fructosyltransferase complex with donor/acceptor substrates reveal complete subsites in the active site for catalysis. J Biol Chem. 2010;285:23251-64.

18. Porras-Domínguez JR. Obtención de Fructooligosacáridos ridos a partir de levanas bacterianas mediante el uso de endo-levanasas. MSc Thesis. http://132.248.9.195/ptd2013/Presenciales/0693615/Index.html. Accessed 2012

19. Chambert R, Gonzy-Tréboul G, Dedonder R. Kinetic studies of levansucrase of Bacillus subtilis. Eur J Biochem. 1974;41:285-300.

20. Song DD, Jacques NA. Purification and enzymatic properties of the fructosyltransferase of Streptococcus salivarius ATCC 25975. Biochem J. 1999:341:285-91.

21. Ozimek LK, Kralj S, van der Maarel MJEC, Dijkhuizen L. The levansucrase and inulosucrase enzymes of Lactobacillus reuteri 121 catalyse processive and non-processive transglycosylation reactions. Microbiology. 2006;152:1187-96.

22. Rodríquez-Alegría ME, Enciso-Rodríquez A, Ortiz-Soto ME, Cassani J, Olvera C, López-Munguía A. Fructooligosaccharide production by a truncated Leuconostoc citreum inulosucrase mutant. Biocatal Biotrans. 2010;28:51-9.

23. Crittenden RG, Doelle HW. Identification and characterization of the extracellular sucrases of Zymomonas mobilis ATCC 39676. Appl Microbiol Biotechnol. 1994;41:302-8.

24. Tieking M, Ehrmann MA, Vogel RF, Gänzle MG. Molecular and functional characterization of a levansucrase from the sourdough isolate Lactobacillus sanfranciscensis TMW1.392. Appl Microbiol Biotechnol. 2005;66:655-63.

25. Bradford MM. A rapid and sensitive method for the quantitation of microgram quantities of protein utilizing the principle of protein dye binding. Anal Biochem. 1976:72:248-54.

26. Miller GL. Use of dinitrosalicylic acid reagent for determination of reducing sugar. Anal Chem. 1959;31:426-8.

\section{Submit your next manuscript to BioMed Central and take full advantage of:}

- Convenient online submission

- Thorough peer review

- No space constraints or color figure charges

- Immediate publication on acceptance

- Inclusion in PubMed, CAS, Scopus and Google Scholar

- Research which is freely available for redistribution

Submit your manuscript at www.biomedcentral.com/submit 